American J. of Engineering and Applied Sciences 3 (3): 569-575, 2010

ISSN 1941-7020

(C) 2010 Science Publications

\title{
The Waiting Space Environment: Perception by Design
}

\author{
Fuziah Ibrahim, Wan Mariah Wan Harun and Muna Hanim Abdul Samad \\ School of Housing, Building and Planning University Sains Malaysia, Malaysia
}

\begin{abstract}
Problem statement: The waiting space is the first point of perception and reality that users would encounter when they visit any health institution. The users' experience in the waiting area is very crucial in determining their preference. The study explored the physical environment of the waiting area which affects the people's anxiety and perception. The physical environment which links with the interior semantics and is part of the language of space speaks volume about the users' needs and preferences. The study discussed the spatial contents within the environment which give comfort to the users. How health care is delivered particular in the first meeting point between the patients and the institution are interpreted. Approach: Combinations of physical observation on sites and in-depth interviews were conducted to find out the real situation of users experience. Results: The physical waiting area characteristics contributed to the comfort or discomfort of the immediate users. The waiting time appears to be the main concern of the users. Conclusion: The findings suggested that the adult patrons are quite happy with the seat design that is the seat affordances the adult users. The seating arrangement could be further enhance for better affordances.
\end{abstract}

Key words: Health institution waiting areas, perception, end users, affordances, interior semantics

\section{INTRODUCTION}

The main aim of this study is discuss the research findings on the experiences of the users in the waiting rooms environment of hospitals. The study would focus on waiting areas in only one hospital. The study requires the exploration of the users' experiences and emotional responses and the relationship between their emotional responses to the physical attributes/characteristics of the waiting area. The study is a respond to Turner (2002) who emphasis that there is a lack research in architecture and design that relate to bio-ethics in medical environment. He adds that medical environment is more concern with morality. There is a need to explore the medical settings towards a more decent, humane and caring medical environment. He emphasis that not much attention is made in the practical arrangement of rooms and hallways, garden, human interaction and works of art to the creation of a more meaningful, decent and habitable spaces.

As such this study discusses this issue highlighted in the series of series of undergoing research (Harun and Ibrahim, 2009; Vihma, 2003). The study focuses on one of the hospital waiting areas. The patrons are patients and those accompanying them in the waiting areas.

The main methods of investigation comprised of observation and information gathering at the sites, face to face interview with the patients and visitors. The observations of the physical attributes of the waiting area were carried by taking notes, photograph and video-recording some parts of the waiting duration.

\section{MATERIALS AND METHODS}

Waiting area attributes: Table 1 shows the characteristics of different waiting areas in the hospital under study.

Waiting area: the observation through images: Figure 1a-c, show the waiting area in the main foyer is rather simple. Metal benches are placed on one side and the opposite site with blue plastic seating. The images were taken around $9.30 \mathrm{am}$, portrayed rather peaceful with only a few people using the seat. The foyer is naturally ventilated. It became quite hot when there is no breeze. It was lighted with fluorescent lamp. There is some attempt to design the interior but lack the coziness feel. However as observed from Fig. 1a, the man lifted up his legs onto the bench and try to get as comfortable as possible while reading the newspaper. $\mathrm{He}$ is able to do that due to the lack of crowd. There was nothing much to do in the area except to wait.

Figure 1d-e shows the walkway or the corridor that stretches from the front foyer right to the end of the building. It is furnished with built-in long 'benches' which the patrons use for seating. It is naturally ventilated as the space is opened with no walls. 
Table 1: The characteristics of different waiting areas

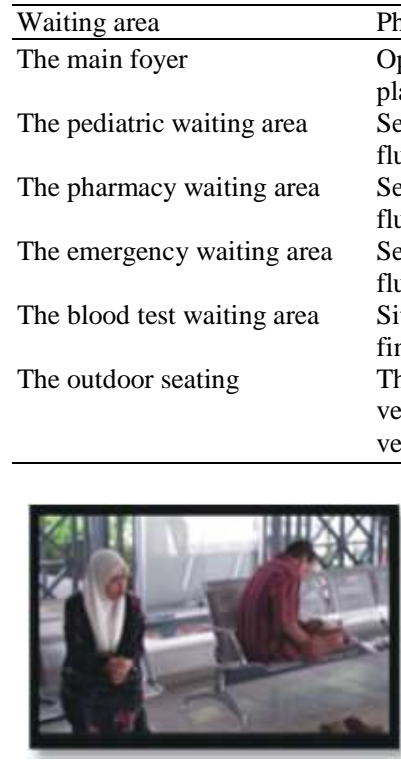

(a)

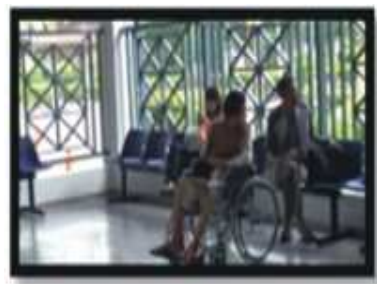

(c)

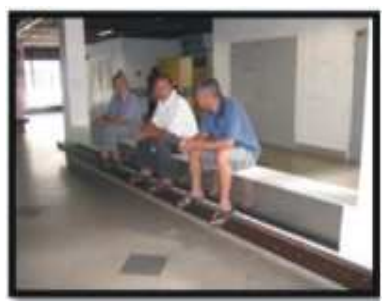

(e)

Fig. 1: (a-c) The waiting area; (d, e) The walkway or the corridor

The pharmacy: Figure 2a-c shows the scene of a typical sociafugal seating arrangement. The indication on the images shows different style of sitting. Although there is ample leg-room in between the rows of seating, a patron however needed to turn $90^{\circ}$ from the intended seating position in order to converse with a friend (Fig. 2a).

Figure $2 \mathrm{~d}$ and e show that the patients with the crutches needs to sit side way due to lack of leg room for him. He needed to stretch his bandaged leg.

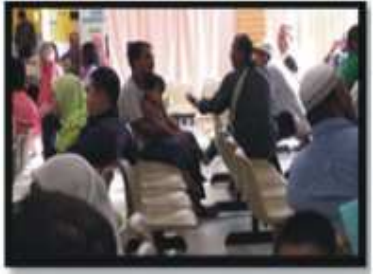

(a)

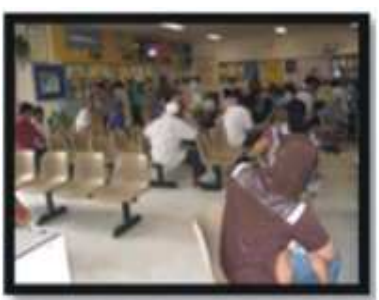

(c)

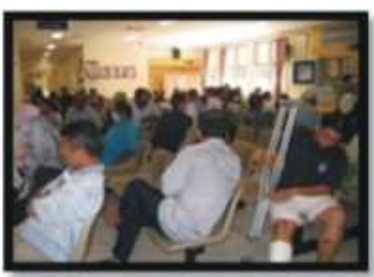

(e)

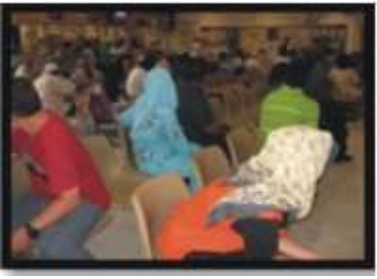

(b)

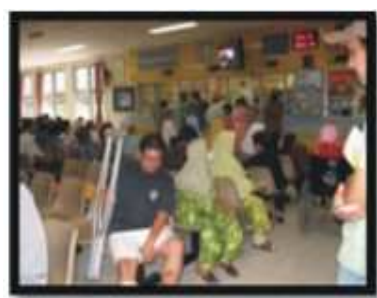

(d)

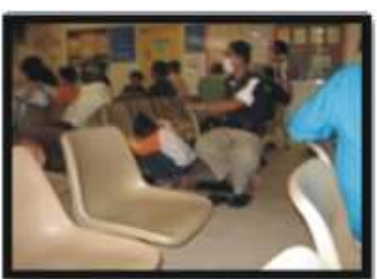

(f)
Fig. 2: (a-c) The scene of a typical sociafugal seating arrangement; (d-f) The patients and the seats

The ladies behind him were also sitting sideways. A TV was placed at the upper part of the main counter was the only means to occupy their waiting time. Some of them were watching a TV programme; some chatting with friends; some waiting patiently for their numbers to be called. One child (Fig. 2f) was using the seat as a table while squatting on the floor. Seats in the middle rows were rarely occupied, or the last to be taken as it was quite a hassle to reach the seat; due to the arrangement of the seat and the small area to get through, not to mention, the crowd. The pharmacy waiting area was fully packed at $11.30 \mathrm{am}$. 


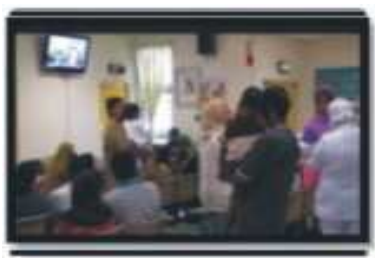

(a)

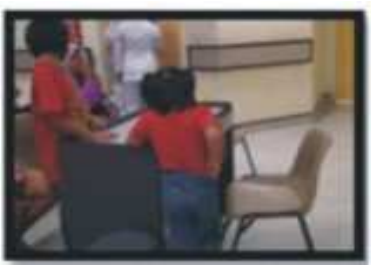

(c)

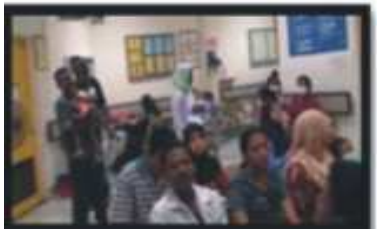

(e)

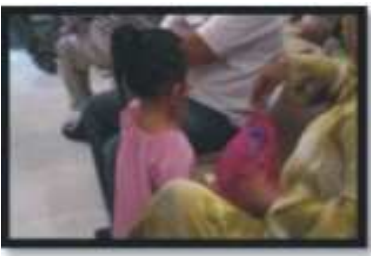

(b)

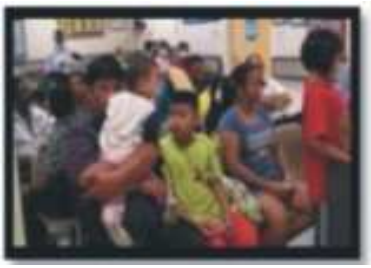

(d)

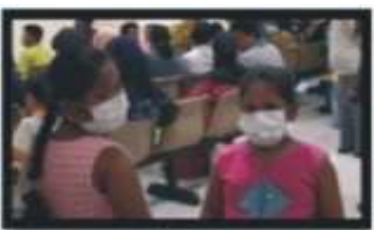

(f)
Fig. 3: The behaviors of patrons and their children in the waiting area

The paediatric waiting area: Figure $3 \mathrm{a}-\mathrm{f}$ shows the behaviors of patrons and their children in the waiting area. Active children seldom sit as shown in the images. They try to find things to amuse themselves. Not much to do in such a small space with too many adult and the other children. As a means to occupy the time while waiting, some parents and children watched TV. However the programmes were not meant for children. Figure $3 \mathrm{a}$ shows that few people were interested in watching. The seating arrangement is sociofugal.

At 9.00 am the place was fully packed. At least 5 parents were standing holding their babies. The toddlers were running around, playing. The children obviously cannot sit comfortably in and adult chair (Dainoff et al., 2007). The seats were not enough to accommodate the patrons every morning. The clinic is for pediatric patients in the morning and in the afternoon is allocated for maternity patients. One of the parent said she always has to wait until $2.00 \mathrm{pm}$ before she could go home.

Besides the lack of seat, the reason for parents standing was due to the agitated and restless children. The parents needed to move about to keep their children calm. Who could blame them, the space was designed without considering the children and their need.

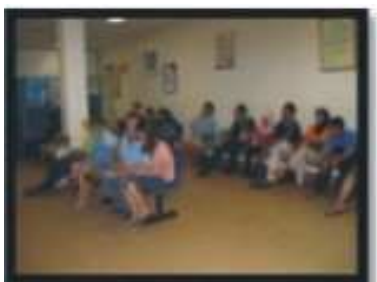

(a)

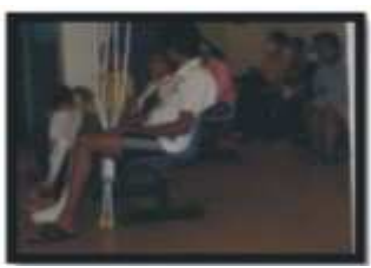

(c)

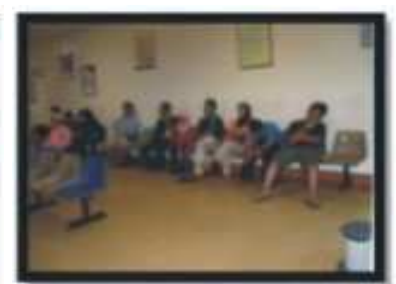

(b)

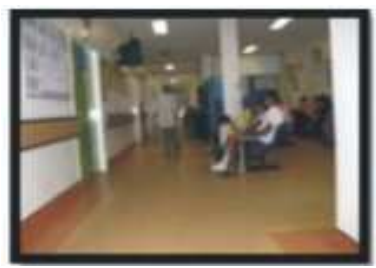

(d)

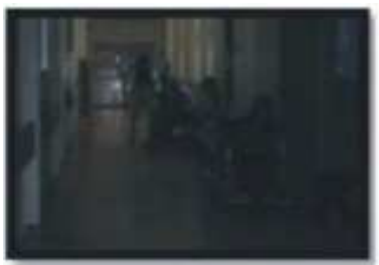

(e)

Fig. 4: The ambiance of the waiting area of the emergency department

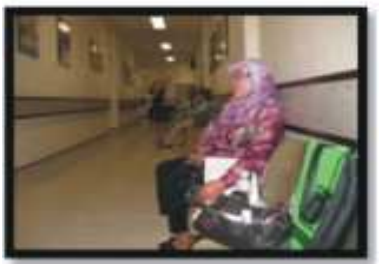

Fig. 5: An ordinary user

The emergency department: Figure 4a-e describes the ambiance of the waiting area of the emergency department. The hospital does not have out-patient department. The public have to come to the emergency department for treatment as out-patients. The seating was sociofugally arranged in two and half rows. The facilities are minimal; a notice board which did not attract attention was placed on one corner of the space; posters and information bulletin were randomly arranged on the wall. The space was ventilated by airconditioning device.

The "heart department" waiting area: Figure 5 shows a lady was waiting for her husband who was undergoing a treatment. She had been waiting for the past two and a half $h$ from 9.00-11.30 am. 


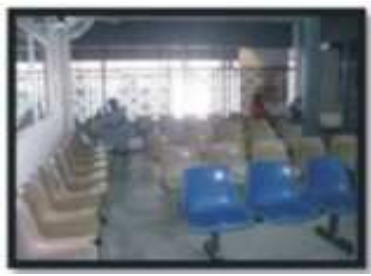

(a)

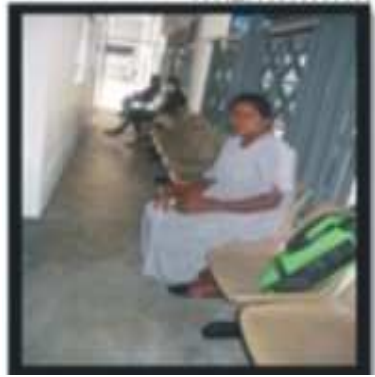

(c)

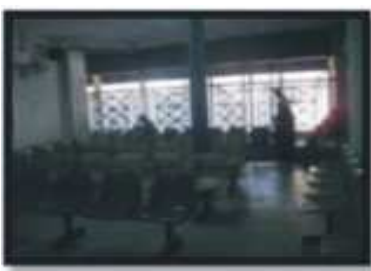

(b)

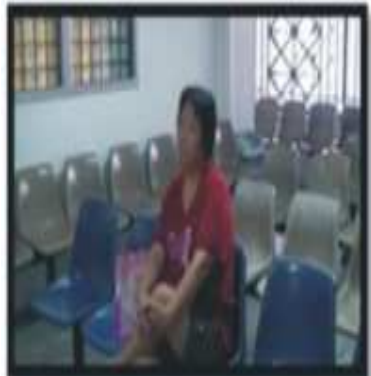

(d)
Fig. 6: The waiting area of the blood test department

She described the chair as comfortable. The space was comfortable with air-conditioning. The area was not crowded, as patients come by appointment.

The blood test waiting area: Figure $6 \mathrm{a}-\mathrm{d}$ shows the waiting area of the blood test department. Few people were around at early noon. However the author was told by the nurse in charge there was always a large crowd earlier, between 7.30-10.30 am. Patients waited for the blood test. The seating were normal plastic chairs with metal legs. The atmosphere was quite hot and stuffy. There was no air-conditioning as the space was open on one side. However the other three sides were walled. When interviewed the pregnant lady said the seat was comfortable for her. She had been waiting for nearly $2 \mathrm{~h}$.

The seating in the surrounding area of the hospital precinct: Figure 7a shows some patrons take the drain as their make shift seating due to the lack of seat. They were occupied with reading, even though drains were certainly not meant for sitting. It was shady but gets hot when exposed to midday sunlight due to the lack of shading.

Figure 7e-g shows seating meant for patrons to rest while waiting. They were people accompanying the patients or the patients themselves. They looked quite comfortable when sitting on the tile-finish concrete bench. The 8 feet long bench was made-in-situ. Some people were able to dose of while seating on it. However they tended to slide to get to the most comfortable position as shown in Fig. 7f.

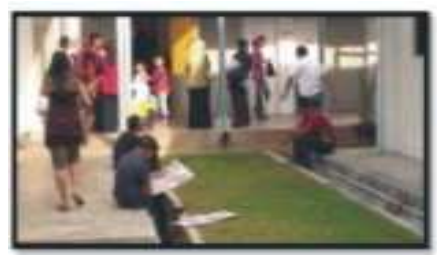

(a)

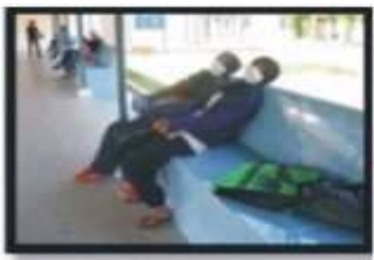

(b)

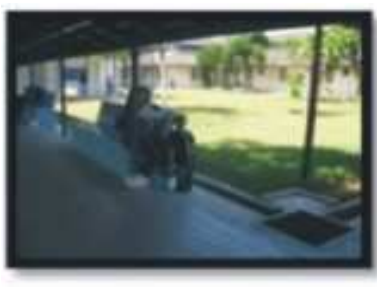

(d)

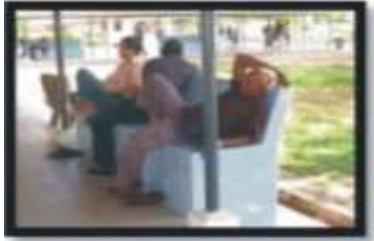

(f)

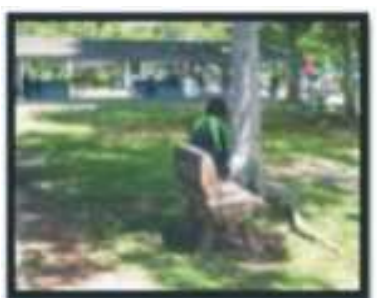

(h)

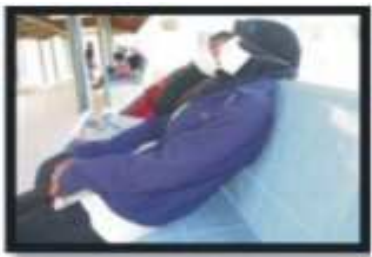

(c)

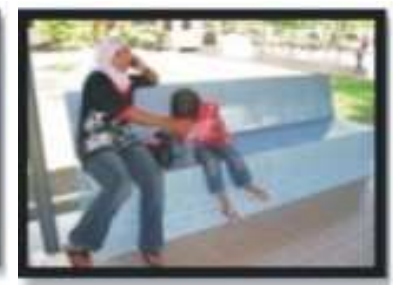

(e)

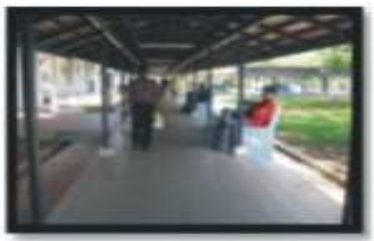

(g)

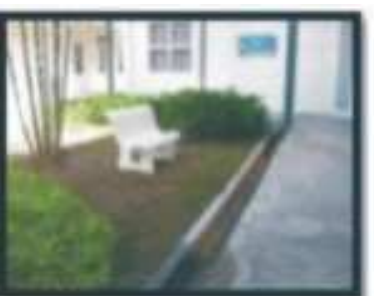

(i)
Fig. 7: The patrons and lack of seating area

Another type of seating found at the surrounding area was the ready-made stone seating. The white stone seating was empty, due to the location outside.

The other type was timber-look concrete bench located further away from the crowd.

\section{RESULTS AND DISCUSSION}

The findings are focus on two main issues, i.e., one the seating, the other is the environment of the waiting 
areas. To summarize, there are 5 types of seating, consisting of different materials and design as shown in Fig. 8.

Each having their own purposes and located at different areas. The injection-molding plastic seating are mostly found in the indoor waiting areas, arranged in linear group of six and is sociofugally arranged; the long in-situ concrete bench that stretch from one column to the other, the outdoor concrete bench; the stone bench; the timber-look concrete bench and the chrome-finish metal bench.

From the semantic point of view the seating above are obviously meant for sitting. The product communicates the intended message, sitting. The seat affords human action, i.e., sitting. Typically all indoor the waiting areas in the hospital have one type of seat in common, the injection molding plastic seat. The seat was designed in the 1960s when designers were experimenting with plastic as the new found material. Since then it was 'copied' and used all over the world since the production is reasonably cheap. The shape and form have not changed much. Is there any semantic value? An object according to Norman (2004), must be human-centered. The seat is humancentered alright.
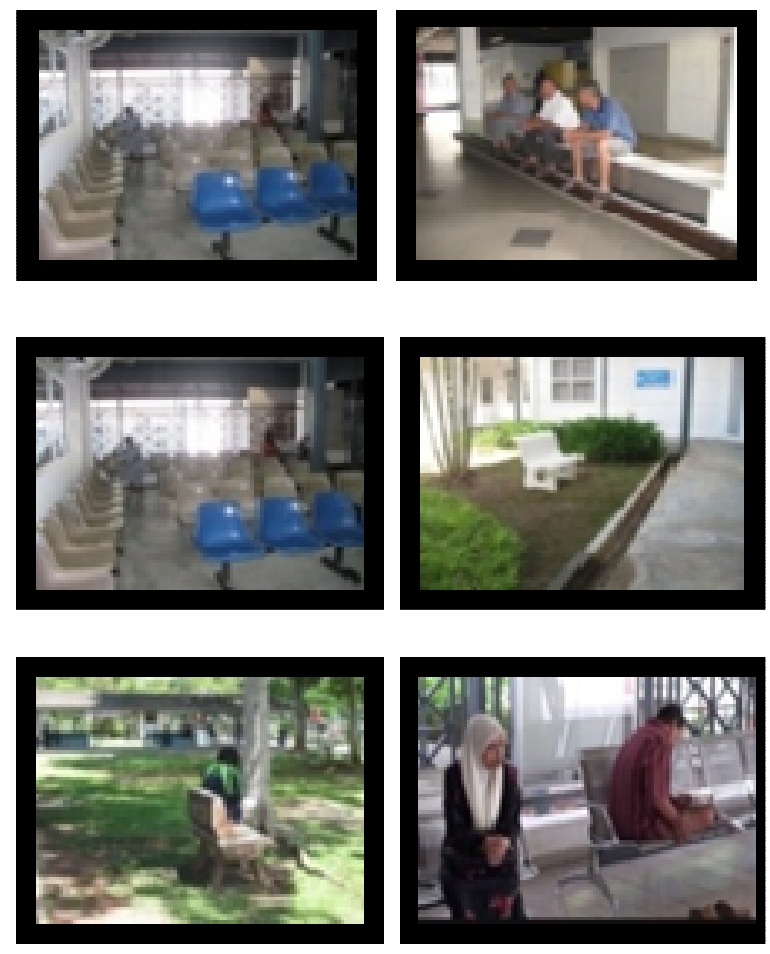

Fig. 8: The different type of seating
Observing children's action in the waiting areas could provide one with the idea what a waiting area should look like. The seat is not design for them to sit properly due to their size, Fig. $2 f$ and $3 a-f$. Some of them use the seat as a desk in which she/he absorb in writing or sketching. Children do not behave in the regular of things dictate for adults. They would like to do something, while the seat, the arrangement and other furniture seems to prevent their action and make them into limited position or action.

Lack of comfortable seating also leads to people going for alternatives such as found in the hospital compound where people split out to the outdoor spaces, sitting along the drains.

Dainoff et al. (2007) claimed that in order to reduce the discomfort, it is important for a chair to provide support and allowing the change of posture. The seat must have dynamic character in affordance to reduce the discomfort. The seat discussed do not have the dynamic character i.e., it cannot be adjusted in any way. Even it cannot be moved since it is tied up together and there is limited space in the waiting area for the arrangement to take place. The entire seats are not universally designed, not only for children but the elderly.

Norman (2004) believes that a product should be functional, beautiful and should have an emotional impact as well. He added that however behavioral design is about use, in which appearance does not matter, but performance plays crucial role. The open ended interview with some of the patrons using the seat describe it as 'comfortable' which put the seat is in the category of behavioral design.

The design must link always link with comfort if it is meant for human. Were the seat comfortable as indicated by the patrons? The author doubts it. The patrons' feed backed may be due to the nature and culture of Malaysia who are mostly complacent with the public facilities provided (Harun and Ibrahim, 2009). In addition it could be that they are unaware of the availability of other comfortable seat design. For the seat to be comfortable the design must fit the visceral and reflective design as mention by Norman (2004).

The sociofugal seating arrangement (Howard, 2009; Lawson, 2001) is chosen by the establishment to accommodate the restricted space for the waiting areas. It discourages human interaction as proven in the observation. No eye contact could be met if people sit next to each other. When sitting next to stranger it is unlikely that anyone will turn round and make eye contact. If eye contact is made in such proximity, one is entering the other personal or even intimate space. The attributes, "crowded" and "uncomfortable" indicate 
such uneasiness among the patrons. Patients who come with spouses or member of their family would be accommodated much better in Sociopetal arrangement, since the radial arrangement would stimulate interaction. Patients with crutches are having difficulties trying to get to the middle seat of sociofugal. They do not much have choice but to sit at the far end or at the front of sociofugal arrangement (Fig. 2a and e, Fig. 4c and d). Suggestion from the research would be the hospital should seriously consider alternative design such as combination of sociofugal and sociapetal arrangement to cater for the issue.

Khoo et al. (1997) claims that there is patient's charter which tells about the right and service that patients can expect. The patients' charter (Khoo et al., 1997) tells that the overall waiting time for outpatient registration is 30 minutes. The research found out that most patrons have to wait $2 \mathrm{~h}$ at least to see their doctors. Abdullah, claims that the average outpatient waiting time is between 5-6 h. Such long duration waiting time would attain for serious attention to give the most comfort for the patrons.

Studies about waiting lines were made by Maister (1985) and Norman (2008). Norman (2008) who modified from Maister (1985) suggested several principles for increasing the pleasantness of waiting; emotions dominate; eliminate confusion: Provide a conceptual model, feedback and explanation; the wait must be appropriate; set expectations, then meet or exceed them; keep people occupied: filled time passes more quickly than unfilled time; be fair; end strong, start strong; memory of an event is more important than experience.

It seems that waiting areas are the least of concern from hospital authorities. Norman (2008) claimed that hospitals are designed with many concerns in mind: the insurance companies, the owners, the administrations, the physicians, nurses and stuff. Waiting areas are usually somewhere at the end of the list. Waiting areas are 'added on'. He added that it is rare that hospitals spend time and effort and finances concerned about the treatment of people in the waiting rooms, or about the emotional state of patients, relative and friends.

The sense of time is altered by our emotions to such an extent that time seems to fly when we are having fun and drags when we are bored (Droit-Volet and Meck, 2007). The negative attributes (Harun and Ibrahim, 2009) seem to suggest that the patrons drag the waiting. They points out that "comfort" attributes is due to most Malaysian readily expressed gratitude and they might not been exposed to better facilities than the ones they had already experienced.
Vihma (2003) points out that instead of being reductive and inhibiting, waiting areas could function as spaces for reflection and communication, they could afford inspiration and amusement rather than direct behavior into limited movements and postures, passivity and dullness. The attributes of waiting such as "bored", "stress", "noisy", "crowded", "hot", "stuffy" (Harun and Ibrahim, 2009) show that the spaces do not inspire the positive affordances. These force disciplines, control and stiffness according to Vihma (2003), could increased mental workload.

Orsborn (2008) emphasis that it is much better to have freestanding seat in waiting area health care facilities so that families could pull the chair together to create a more intimate space. However she added that could add extra task for the staff to rearranging the furniture.

Researched by Dijkstra et al. (2008) shows that healing environment appears to be important determinant in how people feel and act. Although the current study do not include hospitalized patients, but rather the out-patients and the relatives of friends that accompany them within the waiting area environment. Waiting area is supposedly part of the healing environment for these patrons. Being hospitalized is generally associated with feelings of fear, uncertainty and anxiety. The waiting experience would certainly have the same effect. Spaces have value attach to them. It conveys cultural meaning and frames the users' behavior. The present of others within the space has an effect on how we behave and perceive the space (O'Neil et al., 2004).

\section{CONCLUSION}

Although the main research focus on the seat design and the immediate environment of waiting, the findings suggest that the adult patrons are quite happy with the seat design since their comment are 'comfortable' when ask about the seat itself. The issue that arise from the observation and interviews is the waiting time. The average waiting time is $2-3 \mathrm{~h}$. Some even take half a day before the patrons could dismiss. Mobach (2007) claims that in general waiting for service is regarded as a typically negative experience, which may cause impatience, frustration and annoyance. He added that distraction during waiting time will make the waiting time more enduring. Findings by Norman (2008) and Maister (1985) back the claim to the point that they included distraction or making people occupied during waiting as one of the principles in designing waiting lines. Newspapers, aquarium, coffee machine and children play areas are 
some of the 'active ludic space' suggested by Mobach (2007) during waiting times and brochures, internet connectors are 'passive ludic space' which could enhance the quality of waiting. All the waiting areas in the study do not have the facilities as suggested by Mobach (2007).

Combination of sociofugal and sociopetal arrangement of seat could enhance the quality of waiting time as sociopetal enhances closeness and communication whereas sociofugal is suitable for patients who wish not to be disturbed by others. Besides comfort, the emotions arise in waiting would be look into in further research in order to enhance the interior semantics of healing environment. The descriptive nature of the research might be exposed to simplification of the conclusion. Future research work using statistical tool recommended to better handle numerous waiting environments.

\section{REFERENCES}

Khoo, C.M., Y.L. Lim, A. Hakam, Z. Rahmant and A. Sharipah et al., 1997. The patient's chartervalidating actual services provided to the outpatient. JUMMEC, 2: 107-110. http://myais.fsktm.um.edu.my/5649/1/Chin_MK.pdf

Dainoff, M., L. Mark, L. Ye and M. Petrovic, 2007. Forget about aesthetics in chair design: Ergonomics should provide the basis for comfort. ergonomics and health aspects. Lecturer Notes Comput. Sci., 4566: 19-25. DOI: 10.1007/978-3540-73333-1_3

Dijkstra, K., M.E. Pieterse and A.T.H. Pruyn, 2008. Individual differences in reactions towards color in simulated healthcare environments: The role of stimulus screening ability. J. Environ. Psychol., 28: 268-277. http://doc.utwente.nl/60334/

Droit-Volet, S. and W.H. Meck, 2007. How emotions color our perception of time. Trends Cognit. Sci., 11: 504-513. DOI: 10.1016/j.tics.2007.09.008

Harun, W.M.W. and F. Ibrahim, 2009. Humanenvironment relationship study of waiting areas in hospitals. IASDR.

http://www.iasdr2009.org/ap/Papers/Orally\%20Pre sented\%20Papers/Universal\%20Design/Humanenvironment $\% 20$ relationship $\% 20$ study $\% 20$ of $\% 20$ waiting\%20areas\%20in\%20hospitals.pdf
Howard, J., 2009. Sociofugal seating in airports. Word Press.

http://designforservice.wordpress.com/2009/02/15/ sociofugal-seating-in-airports/

Lawson, B., 2001. Language of Space. 1st Edn., Architectural Press, USA., ISBN 10: 0750652462, pp: 272.

Maister, D.H., 1985. The Psychology of Waiting Lines. In: The Service Encounter: Managing Employee/Customer Interaction in Service Businesses, Czepiel, J.A., M.R. Solomon and C.F. Surprenant (Eds.). Lexington Books, Lexington, MA., ISBN: 13: 9780669082739, pp: 114-123.

Mobach, M.P., 2007. Consumer behavior in the waiting area. Pharm. World Sci., 29: 3-6. DOI: 10.1007/s11096-005-3797-z

Norman, D., 2004. Emotional about design. Guidance.co.uk.

http://arts.guardian.co.uk/features/story/0,11710,11 66468,00.html\#article_continue

Norman, D.A., 2008. The psychology of waiting lines. JND. http://www.jnd.org/ms/Norman\%20The\%20Psych ology\%20of\%20Waiting\%20Lines.pdf

O'Neil, E., D. Woodgate and V. Kostakos, 2004. Easing the wait in the emergency rooms: Building a theory of public information systems. Proceedings of the 5th Conference on Designing Interactive Systems: Processes, Practices, Methods and Techniques, Aug. 1-4, ACM Press, Cambridge, MA., USA., pp: 17-25. DOI: $10.1145 / 1013115.1013120$

Orsborn, M., 2008. Inding healthcare furniture that works. Buildings.com. http://www.buildings.com/Magazine/ArticleDetails /tabid/3413/ArticleID/5584/Default.aspx

Turner, L., 2002. Medical facilities as moral worlds. J. Med. Hum., 28: 19-22. DOI: 10.1136/mh.28.1.19

Vihma, S., 2003. On actual semantic and aesthetic interaction with design objects. The Helsinki University of Art and Design. http://www.ub.edu/5ead/PDF/6/Vihma.pdf 